\title{
From analysis/synthesis to conjecture/analysis: a review of Karl Popper's influence on design methodology in architecture
}

Greg Bamford, Department of Architecture, Zelman Cowen Building, The University of Queensland, Brisbane, Queensland 4072, Australia

The two principal models of design in methodological circles in architecture-analysis/synthesis and conjecture/analysis—have their roots in philosophy of science, in different conceptions of scientific method. This paper explores the philosophical origins of these models and the reasons for rejecting analysis/synthesis in favour of conjecture/analysis, the latter being derived from Karl Popper's view of scientific method. I discuss a fundamental problem with Popper's view, however, and indicate a framework for conjecturelanalysis to avoid this problem. (c) 2002 Elsevier Science Ltd. All rights reserved.

Keywords: Philosophy of design, Design process

1 About philosophy, www.arts.uq.edu.au/philosophy/ uginfo.htm\#philosophy (2001) pp $1-2$

2 Granath, J A 'Architecture, technology and human factors: design in a socio-technical context' PhD thesis, Chalmers University of Technology, Göteborg, Sweden (1991)

3 Broadbent, G 'Design method in architecture' The Architects' Journal Vol 144 No 11 (1966) 679-685

4 Broadbent, G Design in architecture: architecture and the human sciences John Wiley and Sons, Chichester, UK (1973)

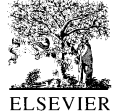

6 What, exactly, might one believe in believing in God?' 'Can a computer have a mind?' (p 1). These are just two of many questions posed in the introduction to philosophy at my university, intended to make the point that we can easily be nudged into considering questions of the kind professional philosophers routinely scrutinise. In architecture, for example, many students take to environmental philosophy because they will be instrumental in re-organising relatively large chunks of the environment and they recognise that this practice now presents fundamental dilemmas. Studying architecture 30 years ago, it was a similar experience for me, and for many others, with the problem of method in design ${ }^{2}$. Attempts to make design more rational or systematic then had, seemingly inexplicably, the opposite effect, and this puzzling experience supplies the rationale for this paper.

Design method came to prominence in architecture at a time when design education was often a desultory affair, and much modernist architecture was the object of popular antipathy ${ }^{3,4}$. But there was another reason for

www.elsevier.com/locate/destud

0142-694X/02 \$ - see front matter Design Studies 23 (2002) 245-261 PII: S0142-694X(01)00037-0

(C) 2002 Elsevier Science Ltd All rights reserved Printed in Great Britain 
5 Jarvie, I C The revolution in anthropology Routledge and Kegan Paul, London (1964)

6 Beck, L W Eighteenth century philosophy Free Press, New York (1966) pp 4-5

7 Matson, $\mathrm{F}$ The broken image: man, science and society Anchor Books, New York (1966)

8 Medawar, $\mathbf{P}$ The art of the soluble Methuen, London (1967)

9 Bamford, G S 'Design, science and conceptual analysis' in J Plume (ed.) Architectural science and design in harmony: Proceedings of the joint ANZASCA/ADTRA Conference, University of NSW School of Architecture, Kensington, NSW (1991) pp 229-238

10 Chalmers, A F What is this thing called science? An assessment of the nature and status of science and its methods, 3rd edn University of Queensland Press, St Lucia, Brisbane (1999) p 53 11 Hempel, C G Philosophy of natural science Prentice Hall, Englewood Cliffs, NJ (1966) this fascination with method. Ian Jarvie remarked at the time that, in the social sciences, scientific method had been deified. Introducing his analysis of cargo cults, Jarvie suggested, with a whiff of irony, that scientific method was itself the object of a cargo cult in these disciplines: 'if worshipped by means of the correct ritual' of 'unprejudiced observation and patient induction', the scientific method would deliver an account of society 'comparable in vigour and success to natural science's (pp xiiixiv). This was not a novel idea. The dominance of science in thinking about method stretches back to the success of Newtonian mechanics in the 18th century when, as Lewis Beck remarked, whatever seemed intractable to Newton's methods 'ceased to be a matter of prime importance to thinkers, or began to seem merely a refuge for superstition and ignorance ${ }^{6,7}$.

During the period from the late 1950s to the early 1970s, however, design did not set out to ape science so much as that the dominant view of 'scientific method'-its actual relations with science were another matter-functioned like an ideology, as a knot of ideas and assumptions that seemed entirely natural for any would-be rational enterprise like design to adopt ${ }^{8}$. Since a principal interest in philosophy lies in analysis of the 'concepts and the language through which our understanding of the world and of ourselves is expressed ${ }^{1}$ ( $p 1$ ), turning to philosophy here offered one clear way of trying to understand this problem and its implications. In this paper, then, I locate analysis/synthesis (A/S), the design method promulgated at the time, in the history of thought about method more generally. And I chart the move to conjecture/test or conjecture/analysis (C/A), a view derived from Karl Popper's account of scientific method. Notwithstanding the views of some misguided critics ${ }^{9}$, Popper's account has made for progress, but it takes us only so far. I indicate this limit and sketch one prospect for overcoming it.

\section{Analysis/synthesis and the history of ideas}

The common traditional view of scientific method (naive inductivism) has been characterised by this statement by a 20 th century economist, A. B. Wolfe:

If we try to imagine how a mind of superhuman power and reach, but normal so far as the logical processes of its thought are concerned ... would use the scientific method, the process would be as follows: First, all facts would be observed and recorded, without selection or a priori guess as to their relative importance. Secondly, the observed and recorded facts would be analysed, compared and classified, without hypothesis or postulates, other than those necessarily involved in the logic of thought. Third, from the analysis of the facts, generalizations would be inductively drawn as to the relations $\ldots$ between them ${ }^{10,11}$. 
The fourth stage in this process is the descent back to the world of facts, drawing predictions and supplying explanations of phenomena by deduction from these generalisations ${ }^{10}$ (p 54).

Compare the above account with the four key stages in A/S (explanatory notes from Broadbent ${ }^{3}$, p 683 and Chris Jones ${ }^{12}$, p 63):

(1) Briefing (programming, data collection).

(2) Analysis (breaking the problem into pieces, formulation of performance specifications, identification of constraints).

(3) Synthesis (ideas generation, putting the pieces together in a new way, design development).

(4) Evaluation (check against performance specifications and constraints, testing to discover the consequences of putting the new arrangement into practice).

Moreover, as a 'first approximation' to the various 'ways ... of thinking' architects require, Broadbent lists, in the following order $^{4}$ (p 18):

(A) Rational thinking (about the nature of the site, the available resources and so on).

(B) Intuitive or creative thinking (about what these results of rational thinking imply for the building form).

(C) Value judgements (as to the relative performance of these various and sometimes conflicting factors).

These various ways of thinking are thus successively enacted in the stages of the design process previously outlined; indeed, it was one aim of systematic methods to so compartmentalise 'logic and imagination'4 (p 257). Thus, Broadbent's rational thought dominates stages 1 and 2 in design, creative thinking is confined to stage 3 , and value judgements (curiously non-rational and non-creative in his schema) occupy stage 4 . In turn, this staged design process itself closely approximates Wolfe's view of scientific method and the ways of thinking he stipulates, allowing for differences between the two practices no analogy could suppress. Wolfe banishes creativity from the early stages in science, for example, and implies it is unnecessary elsewhere, but a place had to be found for it in design. Indeed, Broadbent surmised that the 'creative phase' or synthesis might be given over to even 'wilder flights of fancy', now that it was protected fore and aft by 'rigorous' thinking ${ }^{3}$ (p 683).

Since scientific theories were supposedly logically derived from obser-

12 Jones, J C Design methods: seeds of human futures John Wiley, London (1970) vation, justification came with discovery. Thus, a powerful attraction of $\mathrm{A} / \mathrm{S}$ was not merely that a design would now emerge by a rational process from the brief, rather than spring mysteriously from the architect's fancy, 
13 Hillier, W, Musgrove, J and O'Sullivan, $P$ 'Knowledge and design', in W $\mathbf{J}$ Mitchell Environmental design: research and practice 2, Proceedings of the EDRA 3/AR 8 Conference (1972) pp 29-3-1-29-3-14 (note: page nos after the first reference are given as the last number in sequence)

14 Bacon, $F$ The new organon and related writings The Liberal Arts Press, New York (1960) 15 Descartes, R A Discourse on method Dent, London (1975) 16 Quinton, A Francis Bacon Oxford University Press, Oxford (1980) but a design would be thereby justifiable - as the product of user requirements and other facts, not beholden to the architects' predilections, safe from the tides of fashion, unburdened by history ${ }^{13}$ (p 29-3-5).

To put these ideas into context we need to return to the scientific revolution of the 17th century and the influential writers of the scientific method, in particular, Francis Bacon ${ }^{14}$ and Rene Descartes ${ }^{15}$. Bacon and Descartes both rejected authority or custom as sources of knowledge, contending that individuals had the intellectual capacities to secure knowledge for themselves. As to a method of inquiry, Bacon thought the wrong approach to nature was exemplified by what he called, 'Anticipation of the Mind' ${ }^{14}$ ( $p$ 37). (The history of planetary astronomy in this period, for example, might be construed as the shedding of one deeply entrenched but false 'anticipation' after another: geocentrism, circular orbits, uniform motion.) Bacon catalogued as 'Idols of the mind' various human tendencies, habits, institutions and received ideas which pre-empt or contaminate empirical inquiry, such as the tendency to notice only confirmations of our opinions or our weakness for making hasty or extravagant generalisations ${ }^{16}$. Bacon thought that only sober, organised, exhaustive observation, and cautious generalisation, free from hypothesising, would deliver knowledge. In short, we should not be like spiders, spinning ideas from our imaginations, nor like ants, merely amassing and deploying experience, but like bees, assiduously processing the raw material our senses supply into powerful generalisations (aphorism XCV) ${ }^{14}$. Bacon saw method not so much as a way of organising inquiry, the success of which would still largely depend on our capacities and skills as inquirers (not to mention luck), but as a powerful instrument in its own right, a substitute for such attributes. 'In the drawing of ... a perfect circle', he remarked, 'much depends on the steadiness and practice of the hand, if it be done by aim of hand only, but if with the aid of a ... compass, little or nothing; so is it exactly with my plan'. Indeed, skill or creativity is not merely unnecessary, but may be counter-productive: the 'lame man' who sticks to the designated path will beat the 'swift runner' who strays from it. Because of his fleetness of foot, the latter will finish even further from the truth (aphorism LXI ${ }^{14}$, also Descartes ${ }^{15}$, p 3).

Wolfe's characterisation of science earlier is thus clearly Baconian, and the Baconian legacy in $\mathrm{A} / \mathrm{S}$ is evident in the conviction of the power of method, and in particular in the move to forestall designing and substitute the extensive collection and analysis of unvarnished facts for a prior reliance on 'preconceptions', the Idols of design as it were. With Bacon at his shoulder, Broadbent can thus peremptorily dismiss creativity from 
both briefing - 'one is looking, after all, for facts', and from analysis—-by definition'4 (p 323).

Turning now to Descartes, he says: '[I firmly resolved in my method] to divide each of the difficulties under examination into as many parts as possible, and as might be necessary for its adequate solution'. Then, 'by commencing with objects the simplest and easiest to know, I might ascend, little by little, and, as it were, step by step, to the knowledge of the more complex $^{15}$ (pp 15-16). Here, in plain language, is the kernel of $\mathrm{A} / \mathrm{S}$ decomposition and recomposition ${ }^{17}$ (pp 414-415). Descartes was central in developing the metaphysical view in science of the natural world as a machine ${ }^{18}$. Analysis-and-synthesis is its counterpart in method, as a machine can be disassembled and re-assembled so we may come to understand how it works. In the physics of motion, for example, Galileo had described a method of 'resolution' into variables and 'composition' into formulae or laws ${ }^{19}$ (p 388), and Newton demonstrated the power of synthesis in laws precisely predicting the motion of the heavenly bodies ${ }^{18}$ (pp 44-45).

'Decomposing' problems or 'piecing together' solutions may be important tactics in problem-solving, but a striking disanalogy with design is that, unlike problems in the physics of motion, we do not end where we began. What designers were asked to analyse was a set of requirements and constraints - a rum mixture of individual wants and preferences, social mores and physical conditions - and to 'synthesise' a representation of a possible artifact that would satisfy these various conditions. As Hillier has observed here, these are incommensurable domains: 'architects design form' but can only 'hope for function' ${ }^{17}$ ( $\mathrm{p}$ 424).

\section{Conjecture/analysis and the history of ideas}

In several important respects, Popper inverts the views of method above ${ }^{8}$. Firstly, the idea that scientific inquiry begins with observations or facts, much less unvarnished facts, he thinks is false. Scientific theories are puta-

17 Hillier, B Space is the machine: a configurational theory of architecture Cambridge University Press, Cambridge (1996)

18 Rée, J Descartes Allen Lane, London (1974)

19 Windelband, w A history of philosophy, Vol 2, Harper and Brothers, New York (1958)

20 Koestler, A The sleepwalkers: a history of man's changing vision of the universe Penguin, Harmondsworth, Middlesex (1972) tive explanations, and we seek explanations for what we do not understand or find puzzling, typically, for observations or experience which cannot be accounted for within our existing framework of theories and assumptions. Thus inquiry begins with problems. Secondly, there is no logic or method of discovery that will conduct us, and certainly not in the orderly fashion Bacon or Descartes envisaged, from observation to theory. As Kepler apparently remarked in relation to a chance discovery he had made: 'the roads that lead to knowledge are as wondrous as that knowledge itself' 20 (p 339). Scientific theories are imaginative constructions which typically go well beyond whatever they were designed to explain. Thus, formulating 
21 Morton, A A guide through the theory of knowledge, 2nd edn Blackwell, Oxford (1997)

22 Popper, K R Conjectures and refutations: the growth of scientific knowledge, 4th edn Routledge and Kegan Paul, London (1972)

23 Popper, K R Objective knowledge: an evolutionary approach Routledge and Kegan Paul, London (1972)

24 Laudan L Theories of scientific method from Plato to Mach: a bibliographic review, History of science: an annual review of literature, teaching and research Vol 7 (1968) pp 1-63

25 Medawar, P Induction and intuition in scientific thought Methuen, London (1972)

26 Collingwood, R G An autobiography Oxford University Press, Oxford (1970) hypotheses or conjecturing, contrary to the long-standing Baconian and (apparently) Newtonian prohibition, is indispensable to inquiry. Thirdly, where Bacon and Descartes sought a method that would avoid error at all $\operatorname{costs}^{21}$ (pp 94-95), Popper finds virtue in the unavoidable, the making of mistakes ${ }^{22,23}$. Science is replete with bold conjectures, and a bold conjecture is logically more likely to be false than a conservative one; many explanations are possible for any puzzling observation, only one of which can be true; the most successful theory in the history of science, Newtonian mechanics, turned out to be false, and so on. Thus, criticism, or flushing out error, is the engine of science. With typical rhetorical flourish, then, Popper sums up his method thus:

There is no more rational procedure than the method of trial and error-of

conjectures and refutations; of boldly proposing theories; of trying our best to show that these are erroneous; and of accepting them tentatively if our critical efforts are unsuccessful $^{22}$ (p 51).

It would be false, of course, to imply that philosophy of science was dormant from the 17th century to Popper. 'Conjectures and refutations' is a version of what is generally called the hypothetico-deductive schema, which can be traced back to the 19th century (and earlier) ${ }^{24,25}$. And many of the main features of this schema were widely accepted in philosophy of science by the 1960 s when design methods were on the rise ${ }^{11}$.

To illustrate such a view of method, with an example closer to home, consider the work of R. G. Collingwood, a distinguished early 20th century archaeologist and philosopher. Collingwood proposed an erotetic or 'question and answer' logic of inquiry, such that without a provisional answer to a question already posed, without a firm 'anticipation' of what would be found, prospective archaeologists would do better to stick to digging their vegetable gardens. To illustrate his approach, Collingwood pointed out that the many archaeologists who had previously worked on Hadrian's Wall in northern England 'had never ... seriously asked themselves what it was for'. He continued:

Vaguely you could of course call it a frontier defence, and say that it was to keep out the tribes beyond it. But ... how did it work? Was it meant to work, for example, like a town-wall, from the top of which defenders repelled attacks? Several obvious features about it made it quite impossible that any Roman soldier should ever have meant to use it that way ... and my counter-suggestion [in 1921] that the wall was meant for an 'elevated sentry walk' was generally accepted ${ }^{26}$ (pp 128-129).

Moreover, Collingwood notes: 'a question answered causes another question to arise ${ }^{26}$ (p 129). If the Wall was not a fighting platform, how were 
27 Collingwood R G 'The purpose of the Roman wall' The Vasculum Vol VIII (October 1921) pp 4-9

28 Collingwood, $\mathbf{R}$ G 'Roman signal stations on the Cumberland coast' Transactions of the Cumberland and Westmorland Antiquarian and Archaeological Society Vol 29 (1929) 138-165

29 Couse G S 'Collingwood's detective image of the historian and the study of Hadrian's Wall' Reassessing Collingwood. History and Theory Beiheft 29, Wesleyan University, Middletown, CT (1990) pp 57-77 attackers to be engaged or defeated ${ }^{27}$ What would prevent a raiding party at sea, slipping past the western end of the Wall and landing on an unguarded stretch of the Cumberland coast? Collingwood's answer to the latter question, for example, a question which had puzzled other archaeologists, was that a similar sentry walk to the Wall would be needed here:

But here the sentry walk need not be elevated for sniping was not to be feared. There ought, therefore, to be a chain of [signalling] towers ... resembling those on the Wall, stretching down the coast. The question was, did such towers exist? ${ }^{26}$ (p 129).

A search of the archaeological records to test this hypothesis revealed that just such towers had been found, but largely forgotten. A subsequent field trip identified several likely spots to excavate for other towers, and a network of such towers and associated fortlets, running down this coastline, was eventually pieced together ${ }^{28,29}$.

Turning to design method, then, Popper's ideas moved centre stage in 1972 with the seminal paper, 'Knowledge and design', by Bill Hillier, John Musgrove and Pat O'Sullivan (HMO) ${ }^{13}$. HMO put their finger on the historical baggage of $\mathrm{A} / \mathrm{S}$, and introduced the C/A model of problem-solving as the core of design ${ }^{17}$. They argued that design was 'essentially a matter of prestructuring problems either by a knowledge of solution types or by a knowledge of the latencies of the instrumental set [technological means] in relation to solution types' ${ }^{\prime 3}$ (p 7). In other words, chickens come from chickens, or eggs, not from information about chickens, duly processed, and ... voila! Instead of the vain attempt to displace 'preconceptions', HMO emphasised the role of what they called 'pre-structuring' in defining problems, collecting data and designing; and of the corresponding need for a critical analysis of such pre-structuring - a process they aptly called 'reflexive design'13 (p 7). Rejecting the notion of synthesis as a process by which pieces of a puzzle gradually come together, and so a solution is typically visible only towards the end, HMO argued that conjecturing approximate solutions much earlier in the process than $\mathrm{A} / \mathrm{S}$ allows is what helps to structure an 'understanding of the problem, and to test out its resistances'. And that without a solution-in-principle at some such intermediate stage a 'vast variety of design decisions cannot be taken-particularly those involving other contributors'. 'Design development' can thus be construed as a further process of 'variety reduction' applied to this solution-in-principle, as a family (or tribe) of possible solutions fall away and one putative solution is described in detail ${ }^{13}$ (pp 9-10).

By the end of the 1970s, Broadbent announced, somewhat prematurely, that a new generation of design methods was emerging, one embodying a 
30 Broadbent, G 'The development of design methods-a review' Design Methods and Theories Vol 13 No 1 (1979) 41-45

31 Broadbent G 'Current problems in design methodology' Plan Vol 73 (October 1973) pp 10-12

32 Guerra, F 'A hypotheticodeductive model for design' $A D$ Vol 44 No 4 (1974) 239-240

33 Schön, D The reflective practitioner: how professionals think in action Temple Smith, London (1983)

34 Brawne M 'Research, design and Popper' Architecture Research Quarterly Vol 1 (Winter 1995) 10-15
'Popperian view of designing' ${ }^{30-32}$ (see note 1). However, in 1983, Donald Schön's important book, The Reflective Practitioner, did locate Popper's conjecture/test at the heart of problem-solving in the professions generally $^{33}$ (pp 143-151). Schön identified a dominant strain of 'technical rationality' in professional education, which reduced the epistemology and methodology of professions to that of an applied (positivist) science. He argued that, to the contrary, there were several distinctive features of the problems professionals face or construct which make them intractable to such technical rationality, and proposed a model of 'reflection-in-action' to describe how they were tackled, including, and especially, architectural design.

More recently, Michael Brawne has drawn an analogy between design and Popper's sketch of scientific research as a problem-solving sequence ${ }^{34}$. Popper's schema (which is similar to Collingwood's above) is:

$P_{1} \rightarrow \mathrm{TT} \rightarrow \mathrm{EE} \rightarrow P_{2}$

Problem, $P_{1}$, gives rise to at least one tentative theory, TT, which is a potential solution to $P_{1}$. A process of testing or error elimination, EE, follows, but whatever theory solves $P_{1}$ and thus survives will itself give rise to some new problem(s), $P_{2}$, and so the cycle begins again ${ }^{23}$ (p 287). Brawne illustrates his analogy with Peter Rice's solution to an aesthetic-cum-structural problem in the design of Centre Pompidou, but he imagines that the building itself instantiates $P_{2}{ }^{34}$. An artifact, like Centre Pompidou (or Hadrian's Wall), will be a register of (many of) the problems attempted or solved by its designers, but that is all. A building is not itself a problem, something which can be 'solved'. And like many analogies, the differences may turn out to be as instructive as the similarities. For example, architectural problems, however precisely defined, seem to tolerate many, potentially equally good, solutions. Also, there seem to be problems or dilemmas or ideas in the Arts generally which, however often they are 'explored', have no agreed solution or resolution. For example, 'Is equality more important than liberty?' 'How should a building relate to its context?' On the face of it, then, design looks to have interesting differences from science, or history.

\section{Understanding method}

In this section I complete the critique of $\mathrm{A} / \mathrm{S}$, with the general aim of indicating how to better understand method, in part by invoking distinctions common in philosophical analysis. I confine myself to five points and discuss a case of design teaching involving both $\mathrm{A} / \mathrm{S}$ and $\mathrm{C} / \mathrm{A}$ to illustrate some of these points.

Firstly, is 'analysis' or 'synthesis' a way of thinking and working, or is 
each an episode in which different ways of thinking and working occur? Briefing, for example, ought both to be a critical and a creative process: an existing solution type may no longer be appropriate; prospective users may be uncertain of all their requirements or the implications of them; the architect may want to convince her clients to add an environmental agenda to the program, and so on-all occasions calling for or enacting such ways of thinking. The emergence of community architecture underlined how unsatisfactory the briefing process itself can be, at least where disempowered users are concerned, and new ways of even getting to a brief had to be found. So much is perhaps obvious. However, there is a kind of problem here which I call a meta-problem that deserves recognition. A meta-problem is a problem with the presuppositions of a design problem. Thus, where the solution to a design problem is a design, the solution to a meta-problem is a conceptually reconstructed design problem, or perhaps a problem of some altogether different kind. Imagine a premature babies' ward which looks and functions like a high-tech laboratory, and in which all concerned accept this situation as natural or unavoidable. A brief for an extension to this ward will presuppose an environment of the same kind unless someone (doctor, nurse, architect) thinks to challenge this presupposition: would the babies do better if the environment were different? Could the ward look and run like a nursery, albeit with special equipment and requirements, but with babies no longer mere extensions of the machines and back-up laboratories necessary for their survival? Thus, a re-conceived brief-a putative solution to this meta-problem-will still leave as much (or more) designing to do as before, and will itself be a conjecture: will the babies do better; will staffing costs rise in the new ward, and so on (see note 2)?

Secondly, in A/S, analysis presupposes or depends upon a prior synthesis, and anticipates a solution field, however general or ill-defined, to give meaning and direction to it. For example, a matrix of room relations (employed by A/S design methodologists) is intended to codify desired relations between proposed rooms ${ }^{4}$ ( $\mathrm{p} 260$ ). In this case, the prior synthesis is a set of room types, with all the beliefs, values and memories of particular rooms each of the participants in the process will bring to the task of codification. We can try to empty the elements of the matrix of this content, of course, with talk of 'space' and 'function', but this is a limited tactic for special occasions. (As a universal injunction, diligently pursued, it would leave us in need of that philosopher's stone to turn data about chickens into chickens, as we have seen.) The prior synthesis buried in such a matrix discounts, for example, solutions not involving discrete spaces or in which relations between groups of rooms are primary. Another presupposition is that people can articulate swags of preferences for relations between possible rooms, based on their knowledge and experience 
(however limited), which are such that any design which would not satisfy those preferences would thereby be counted inferior or rejected. How implausible or restrictive is that? The matrix also typically presupposed that users do not disagree amongst themselves or with their architects about such relations, and conflicts with meta-preferences were ignored. For example, the near universal motivation to organise buildings, sites or whole neighbourhoods for ease and convenience of human movement appears to have led us into conflict with our wide-spread meta-preference for being able to get or stay fit 'naturally' or to enjoy the health consequences of such levels of fitness. All analytical techniques have such presuppositions or theoretical commitments. For example, consider two analyses of the same site, one driven by and the other ignoring current environmental concerns. Even where the data for, or the object of, each site analysis overlaps, each will be conducted with different ends in mind, marking out different solution fields.

This illusion of universal data collection and processing, uncontaminated by theory, is put into modern garb in this recent defence of $\mathrm{A} / \mathrm{S}$ : 'The essence of critical thinking is enquiry to exhaustively determine the nature of a problem before proceeding to attempt its solution' ${ }^{35}$ ( $\mathrm{p} 418$ ). However, if this claim were true then designing would itself be no help in understanding problems (and where would this leave the novice designer, in particular?). Moreover, some aspects of a design problem are the product of ideas generated or decisions taken in designing. And finally, clients (and architects) may reasonably only appreciate some aspects of a problem with a design to consider.

Thirdly, the Cartesian legacy in A/S that problems, like machines, can be dismantled and solutions assembled from individually designed pieces, gives an undue autonomy and priority to parts. It is an implausible ontology for artifacts, like architecture. In design, the whole or aspects of the whole govern the parts (which is largely why even bad buildings tend to be relatively coherent). The parts of a design problem are conventionally or tactically determined, even if we often treat them as discrete entities. Thus, rooms are typical parts, but if need be they can be further pulled apart. Moreover, the whole can have attributes that need not be attributes of any part, for example, the form of a building may resemble a ship without any part of the building resembling anything nautical. Recalling HMO's notion

35 Mann, D A 'Teaching designing: the second-year studio at the University of Cincinnati' Design Studies Vol 13 No 4 (1992) 411-430 of variety reduction, designing is, in this respect, more like sculpting a figure from a block of stone than assembling a carburettor. At the beginning, the solution field is infinite; however, at some intermediate point, the sculptor achieves a lumpy but more or less recognisable form-a solution- 
in-principle. This shape could still turn out to be many different figures but with further, ever more detailed work, a particular figure emerges.

Fourthly, is a method of design an account of how competent practitioners design, or is it intended to form or channel the efforts of novices in an educational setting? This is an important, if rarely addressed, question because novice designers obviously differ from competent practitioners in important ways. For example, the former identify form with function in a way the latter have learned to readily uncouple and, unlike the latter, they are as yet incompletely acculturated in the discipline or profession. Thus, the 'preconceptions' novices bring to design are typically resilient and were often deemed inappropriate. A/S sought simply to banish them. Leaving aside the impossibility of doing so, however, why should architects also be asked, with every new problem, to leave their experience at the door?

Fifthly, what is a method of design: does it describe how design proceeds, or how the author of the method thinks it ought to proceed? C/A is essentially descriptive, while $\mathrm{A} / \mathrm{S}$ is essentially prescriptive- a fact which reflects their respective origins in the development of scientific method. $\mathrm{C} / \mathrm{A}$, as it stands, is a relatively weak or minimal claim about how anything that is a problem would be rationally solved: first get an idea, then test it. C/A is historically important, however, because, apart from being true, it implies that all design (with some minimal claim to rationality) proceeds in this fashion, including design supposedly done by A/S.

With this fifth point in mind, I turn to Dennis Mann's account of the second-year studio at the University of Cincinnati, which is framed by design methodology ${ }^{35}$. Cincinnati begin with $\mathrm{C} / \mathrm{A}$, setting their students four, one week design programs of some complexity - for example, a bank or a library-for each of which the students are to produce a solution-inprinciple. Three weeks is then devoted to developing one of these conjectures, feeding in new information such as specific user requirements, climatic conditions, even a site. And as Mann notes, introducing site characteristics will 'automatically lead to a modification of the conjecture' ( $\mathrm{p}$ 416). Next, Cincinnati teach $\mathrm{A} / \mathrm{S}$ in the context of a much simpler, three week design-and-build project, for example, to 'provide the required physical support' for an adult to move from one position to another, $4 \mathrm{ft}$ higher within a relatively confined space.

Mann says that $\mathrm{A} / \mathrm{S}$ is 'thought to be more systematic, rational and logical' than C/A, as well as more 'critical and analytical in its early stages' ${ }^{35}$ (pp 417-418). These remarks may be true of the method Cincinnati has devised, which they call conjecture/analysis, but they have simply ignored 
36 Shapere, D Galileo: a philosophical inquiry University of Chicago Press, Chicago (1974) pp 140-141

37 Bamford G S 'Popper and his commentators on the discovery of Neptune: a close shave for the law of gravitation?' Studies in History and Philosophy of Science Vol 27 (June 1996) pp 207-232 most of HMO's argument in doing so, including that designing by $\mathrm{A} / \mathrm{S}$ is largely an illusion. The basic error in the Cincinnati approach, however, originates in the conflation of description and prescription I have identified above. They treat $\mathrm{C} / \mathrm{A}$ as a recipe or technique, like $\mathrm{A} / \mathrm{S}$, and, on the principle of horses for courses, devise studio programs to suit. In the C/A studio program, each project is relatively complex, the time available for design is severely compressed and relevant information is withheld. What are their novices to do but guess, in the sense of adopt a wildly speculative or arbitrary approach? This misses the point entirely: if we learn that a process involves more guesswork than we had previously thought was the case, that is no reason to introduce even more guesswork into that process. (It is as if the character in Molière's Le Bourgeois Gentilhomme, surprised to discover he had been speaking prose all his life, should then imagine his every word was worthy of publication.) To see how wide of the mark Cincinnati is, recall Collingwood. His inquiry began with a critical reflection on the existing state of archaeological knowledge of the Wall, and in formulating his various hypotheses, he drew on evidence about the Wall, the organisation of the Hadrianic frontier, Roman military operations and engineering standards generally ${ }^{27}$. He did not deliberately put himself into a problem situation about which he was largely ignorant (to enhance the conjectural character of his ideas) and just start guessing.

\section{Popper's problems with conjectures}

There are problems with Popper's ideas about the role and nature of conjectures, however, which are not recognised or broached in the design literature. In this section I will draw attention to them, discuss one fundamental problem, and surface again to indicate some implications for design.

Where Bacon banished hypothesising from science, Popper crowds the landscape with bold conjectures, and the problems with his move are both methodological and epistemic. In terms of method, the hypothetico-deductive model in general ignored the patterns of thought or reasoning involved in arriving at hypotheses, because this process is irrelevant to the acceptance or rejection of such hypotheses. Winning this battle against the inductivism we examined earlier, however, does not show that an adequate account of rationality in science (or design) can afford to ignore such patterns $^{36,37}$. Clearly, not all possible patterns of conjectural thought here are rationally defensible or (would be) employed by problem-solvers. Secondly, although Popper says that science works by 'conjecture and refutation', he means 'conjecture and refutation of major theories'. His first thought when prediction fails is to blame the theory from which that prediction was derived, whereas this is often the scientist's last thought. Thus he cannot explain why, for example, 60 years after the discovery of Uranus, 
38 Miller, D w Critical rationalism: a restatement and defence Open Court, Chicago, IL (1994) 39 Audi, R (ed) The Cambridge dictionary of philosophy Cambridge University Press, Cambridge (1995) p 235 40 Armstrong, D M Belief, truth and knowledge Cambridge University Press, Cambridge (1973)

41 Bamford G S 'Popper, refutation, and "Avoidance" of refutation' PhD Thesis, The University of Queensland, Brisbane (1989) www.architect.uq.edu.au 42 Watkins, J W 'On Stove's book, by a fifth irrationalist' Australasian Journal of Philosophy Vol 63 (1985) 259-268

43 Popper, K R Logic of scientific discovery Hutchinson, London (1972) when astronomers still could not predict the movement of this planet using the law of gravitation, this failure did not persuade them that the law was refuted (or even imperilled) and so should be replaced. Instead, two young astronomers (correctly) conjectured, more conservatively, a previously unknown exterior planet to explain Uranus's meanderings ${ }^{37}$. These features of Popper's account certainly encourage or endorse more arbitrary and extravagant guesswork in problem-solving-of the kind Cincinnati indulge-than is warranted ${ }^{38}$ ( $p$ 9). But it is Popper's epistemology which presents the fundamental difficulty, to which I now turn.

Philosophers have traditionally defined or understood knowledge as justified true belief. This definition is now rejected as unsatisfactory or incomplete, but few would not retain truth as a necessary condition for knowledge $^{39,40}$, which corresponds with the common sense view ${ }^{21}$. Thus, we know that Utzon designed the Sydney Opera House, for example, only if it is true that he did so. Popper, however, long ago rejected this standard condition. His view is that knowing that $p$, where $p$ is a proposition, implies that $p$ is accepted as true, not that $p$ is true (although it may be). However, since a proposition can be both false and accepted as true, his view is at odds with the standard view. The same goes for refutation. Refuting $q$ means proving or demonstrating that $q$ is false. However, if the best we can do with the premises of a falsifying argument is to accept them as true then that is also the best we can do with its conclusion. Thus, refuting $q$ amounts, in this respect, to accepting as true that $q$ is false (that is, accepting $q$ as false), which is consistent with $q$ being true ${ }^{41}$.

John Watkins attempts to defend Popper's radical semantics of 'know' by pointing out that The Oxford English Dictionary gives 'branch of learning' as one meaning for 'knowledge', without suggesting that all such learning should be true. Thus it would be correct to say, Watkins asserts, that 'medical knowledge in the 18th century was very defective and contained much that was downright false' ${ }^{42}$ ( $\mathrm{p} 261$ ). This is true, but irrelevant. A branch of learning is not something that can be true, so Watkins's argument is not relevant to deciding whether or not something that can be true, namely learning, constitutes knowledge if it is not true. By equivocating between 'branch of learning' and 'learning', between 'medicine' and 'medical knowledge', Watkins takes the fact that because, in each pair of terms, the former is not such as can be true, the latter need not be (to constitute knowledge).

In any event, why does Popper adopt such a weak position on knowledge (and refutation) (see note 3)? He adduces several arguments for his position, the most important of which turns on the fallibility of experience ${ }^{22,43}$. 
44 Musgrave, A E 'Falsification and its critics' in $\mathbf{P}$ Suppes, L Henkin, A Joga and G Moisil (eds) Logic, methodology and philosophy of science IV: Proceedings of the 4th International Congress for Logic, Methodology and Philosophy of Science, Bucharest, 1971, North-Holland, Amsterdam (1973) pp 393-406

45 Hinckfuss, I C 'A note on knowledge and mistake' Mind Vol 80 No 320 (1971) 614-615 46 Evans, J L Knowledge and infallibility St Martin's Press, New York (1978)

47 Stove, D C Popper and after: four modern irrationalists Pergamon Press, Oxford (1982) 48 Popper, K R 'Replies to my critics' in P A Schilpp (ed.) The philosophy of Karl Popper, Open Court, La Salle, IL (1974) pp 961-1197
This argument, put simply, is that since mistakes are always possible in observation or experiment, however skilful or meticulous we may be, we therefore cannot know anything, in the standard sense of 'know'44. But it does not follow from the possibility that I am mistaken about something that I am so mistaken, and thus that I do not know. So one can accept the fallibilist premise that mistakes are always possible without being driven to the sceptical conclusion that one cannot know anything (see note 4$)^{45}$. J. L. Evans has drawn a helpful analogy here between 'know' and other achievement verbs like 'win' and 'arrive'46 (p 40). I can win a race or arrive at my destination even though it was always possible I would not do $\mathrm{so}^{41}$.

Whatever we make of such arguments, the important point here is that Popper settled for a view of scientific knowledge as ultimately a matter of professional agreement among scientists about how the world is. In the simplest case of an observation statement (or 'basic statement'), $p$, for example, knowing consists just of scientists agreeing to accept $p$ as true. Mere agreement would be arbitrary, however, and Popper offers this analogy with a jury verdict to give his position substance:

The verdict plays the part of 'a true statement of fact' ... a basic statement, as it were. But it is clear that the statement need not be true merely because the jury has accepted it. This fact is acknowledged in the rule allowing a verdict to be quashed or revised. [Nonetheless] the verdict is reached in accordance with ... certain fundamental principles which are chiefly, if not solely, designed to result in the discovery of objective truth $^{43}$ (p 110).

This analogy may seem to offer a plausible, suitably modest basis for an epistemology in these sceptical times-leaving aside the disanalogy that, unlike a basic statement in science, no jury verdict results, or can result, from a jury having observed the (alleged) commission of the crime in question. But neither Popper nor most of his supporters seem able to swallow the implications of his view. This does not show his view is false, of course, but it offers us scant incentive to adopt it when they cannot consistently do so. When difficulties arise in explaining how science works, for example, Popperians readily fall into equivocation between the standard view of knowledge (as requiring truth) and Popper's weaker view (as requiring only the appearance of truth $)^{47}$. To suit the occasion, Popper will shift, for example, from refutation as $\operatorname{disproof}^{48}(\mathrm{p} 1110)$ to refutation as 'sheer guesswork' about 'what has gone wrong'22 (p 239). I elsewhere provide numerous examples of such practices and their implications ${ }^{41}$ (ch 1 ), and confine myself here to the following example.

In Popper's world, if ornithologists agree that a bird is a black swan they 
refute all swans are white, $q$. If they later reconsider this observational record, however, and reject it as unreliable, $q$ is then not refuted (at least not on this record). So what should they say at this later time about what they had previously said about the truth status of $q$ ? They should still say that $q$ was refuted. After all, they did agree that the bird in question was a black swan and, on Popper's account, that refuted $q$. But to admit that a theory might be refuted at one time and not refuted at some later time would imply relativism. So in cases where the observational record has been thought sufficient to refute a theory (or Popperians have otherwise taken it to be so), and it later turns out not to be so, Popperians say that the theory was only prima facie or apparently refuted on that earlier occasion $^{37,41}$. Thus, they too reserve 'refuted' for just those cases where what is refuted is false, a move that is not open to them. Deciding now that the observational record was unreliable does not alter an earlier decision to the contrary. Recall the jury analogy. If an appeal court quashes a jury verdict it is not denying the jury did reach that verdict. Indeed, it is affirming this fact in quashing the verdict, and it is certainly not saying the jury only reached a verdict of, say, 'apparently guilty'.

To sum up, then, Popper's scepticism did not move him to deny that we have knowledge, scientific or otherwise - this would have dealt him out of the game. Instead, he redefined knowledge in such a way as to admit false beliefs, to describe all knowledge as, ultimately, conjecture. In the end, then, his theory of scientific method is the theory of conjecture and conjecture. But when, for example, medical scientists like Lewis Thomas ${ }^{49}$ or David Weatherall ${ }^{50}$ remark that, historically, medicine 'consisted of sheer guesswork... Anything that could be dreamed up for the treatment of a disease was tried out;' or that medical 'research' once involved the 'most frivolous and irresponsible kind of human experimentation, based on nothing but trial and error, and usually resulting in precisely that sequence! '49 (my emphasis, p 26), are we to deny their distinctions between medical research then ... and now (current failings aside)? And if we do, how much light would we shed on medicine or medical research?

49 Thomas, L The Medusa and the snail Viking Press, New York (1979)

50 Weatherall, D Science and the quiet art: medical research and patient care Oxford University Press, Oxford (1995)
The upshot for design is, I think, clear: whilst we should endorse the general thrust of Popper's method, translated as C/A, we should reject his epistemology. Thus, we can reasonably hold that problem-solving involves guesswork, yet also that (at least some) solutions are knowable or demonstrable (and not merely solutions that are accepted as such). Such distinctions are woven into the fabric of the thought and action of designers (and methodologists like HMO or Schön), no less than medical scientists. 


\section{A taxonomy of tasks in design}

Whilst much in design is conjecture, much is not. All designing involves some guesswork, and all but the simplest designs can reasonably be described as hypotheses or, in some respects, conjectures, given the usual unknowns and uncertainties. But like medical research the texture of design is not literally trial and error; it is not unremitting guesswork. We do know a thing or two. Thus, to develop or better situate the C/A model in design, I think a more fine-grained analysis of the tasks designers tackle is needed, and I conclude by illustrating this point in the context of two suggestions, one by Broadbent, the other by Schön.

Broadbent's well-known 'design spectrum'-algorithm, ratio, deduction, analogy, induction, metaphor, and chance-was an attempt to chart the breadth of thinking in synthesis ${ }^{3,4}$. One problem with it, however, is that although 'algorithm' and 'chance' are poles apart, it is not a spectrum: to employ a ratio as he does is to reason deductively, for example, and arguments by analogy are inductive arguments ${ }^{51}$. But this 'spectrum' does remind us of the diversity of tasks in design - from a chore, such as a parking layout, for which we may follow the near-algorithms of well established office practice, to a problem which confounds the designer's every intuition or move. The designer's lot can be a mixture of such disparate tasks.

Schön describes the way in which a visually literate computer program for structural design (GROWLTIGER) enables architecture students to represent their conjectures visually and intelligibly, as well as calculating the structural consequences and indicating the acceptability of their conjectures (in terms of stress, deflection, etc.). Schön concludes that this shows the 'positivist epistemology of practice [which] emphasises a retrospective view of science as a body of facts, theories and techniques which professions like architecture are meant to apply' is wrong headed, and that 'when we experience science and architectural designing as before-the-fact inquiries, we become aware of their deep similarities' ${ }^{52}$ (p 10). The latter claim is true and important, but I draw a different conclusion from the former. What Schön's account shows is how, on the contrary, a 'positivist' or after-the-fact science does have a place in design. GROWLTIGER defines and solves problems using 'technical knowledge', but this use or

51 Skyrms, B Choice and chance: an introduction to inductive logic, 3rd edn Wadsworth, Belmont, CA (1986)

52 Schön, D A 'Towards a marriage of artistry and applied science in the architectural design studio' JAE Vol 41 No 4 (1988) 4-10 application needs to be appropriately integrated with the designers' characteristic way of thinking and working, that is, with C/A. Schön's example actually shows how guessing and (technical) knowing, ideas and algorithms, are part of one problem-solving process in design.

In conclusion, then, I suggest a taxonomy of tasks is needed-for example: 
chore, tightly and loosely structured problem, meta-problem-framed and tested in situ, that is, in the context of the practice of architects rather than studios of novices, and embedded in architectural culture and history.

Notes

1 Broadbent's sea change on method was curious for he had originally been unmoved by Popper ${ }^{3,4}$. Following $\mathrm{HMO}$, however, he abandoned his former position as if he had never occupied it, declaring that Popper gave the lie to much in design methods ${ }^{30}$, and suggested the parallel between science and design HMO had drawn was 'hardly surprising'30 (p. 44).

2 This case is a 'thought experiment', but it is based on an account of alterations that were made to such a hospital ward. The premature babies did better, physically and mentally, and staffing costs did not rise. (ABC Radio National, Life Matters, 20 February 1992).

3 A related, equally counter-intuitive plank of Popper's epistemology is that evidence is not 'truth enhancing', that there is no such thing as good or positive reasons for holding or accepting that, for example, asbestos dust is carcinogenic ${ }^{38}$.

4 lan Hinckfuss argues that the plausibility of this argument from fallibilism rests on a fallacy ${ }^{45}$. Suppose that from the premises, 'If I know I must be right' and 'It is always possible I am wrong', we draw the conclusion, 'Therefore, I do not know'. This argument is valid only if the first premise is the claim that knowing implies necessarily being right. Being right about anything, however, is a contingent matter, so this premise is false. A first premise which would be true is, 'Necessarily, if I know then I am right', in virtue of the meanings of 'know' and 'right'. But in this case, the argument is invalid. If we equivocate between these two interpretations of the first premise, however, we may think we have both a valid argument and a true first premise (to go with our true second premise), and thus that scepticism follows. 